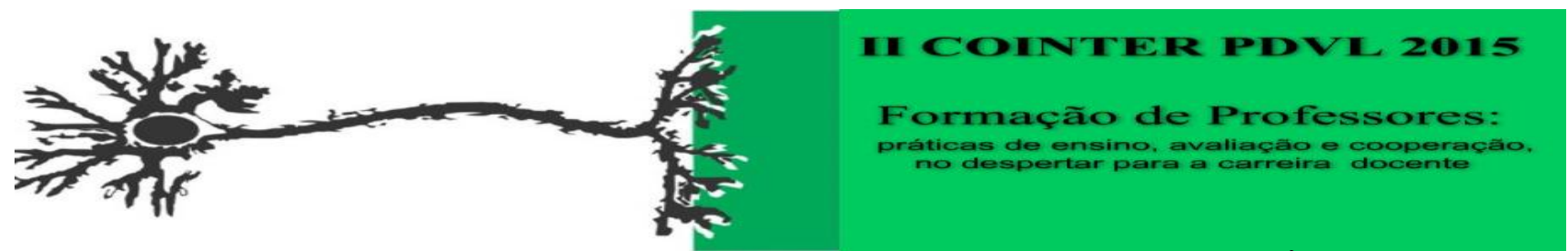

\title{
CONTRIBUIÇÕES DO PENSAMENTO DE ERIK ERIKSON À IDEIA DE FORMAÇÃO HUMANA E À EDUCAÇÃO
}

\author{
Apresentação: Comunicação Oral \\ Isabela Ribeiro Villares Nascimento ${ }^{1}$; Edvânia dos Santos Alves ${ }^{2}$; José Policarpo Júnior ${ }^{3}$
}

\begin{abstract}
Resumo
Este artigo tem por objetivo contribuir com os estudos sobre os princípios da formação humana e sua expressão no pensamento da teoria psicossocial de Erikson e da teoria do desenvolvimento moral em Kohlberg. Constrói um caminho de reflexões a partir de conceitos que tecem diálogos acerca da formação do humano nas perspectivas filosóficas, educativas, psicológicas e antropológicas, na crença de promover, por meio da formação, aquilo que, no humano, pode e deve ser elevado à condição de expressão de sua perfeição ou atualização.
\end{abstract}

Palavras-Chave: formação humana, teoria psicossocial, educação.

\section{Introdução}

A reflexão sobre a influência de dois representantes clássicos da Psicologia no âmbito da Educação reconhece a influência exercida pela obra desses autores do século $\mathrm{XX}$ ao campo educacional. A razão, portanto, para tratar esses autores em um texto referente à área da Educação parte do pressuposto de que as teorias confluem nos campos e áreas de investigação científica e acadêmica.

Não se pretende aqui analisar a repartição do campo científico em suas disciplinas gerais e específicas, reconhecendo-se que estas não são completamente arbitrárias, mas obedecem a práticas e tradições instituídas com sua racionalidade específica; todavia, é necessário que se ressalte o fato - que deveria ser óbvio, caso a divisão científica do trabalho já não estivesse tão arraigada nas mentes dos acadêmicos - de que há uma distinção originária e jamais superada entre os fenômenos a serem conhecidos e compreendidos e a estrutura epistêmico-institucional adquirida pela ciência, de modo que os primeiros não se reduzem à última (cf. GALEFFI: 2003, p. 63-75 e GALEFFI: 2009). Tal distinção ganha ainda maior relevância quando se consideram especialmente aqueles fenômenos que, por sua natureza intrínseca, se manifestam nas zonas limítrofes da classificação estabelecida entre dois ou mais campos científicos. Acreditamos ser precisamente esta a condição da temática que ora nos ocupa, uma vez que a mesma se apresenta como um objeto constituído na

\footnotetext{
Pedagogia, Universidade Federal de Pernambuco - UFPE - isabelavillares@ yahoo.com.br

Pós-graduação em Educação, Universidade Federal de Pernambuco - UFPE - edvaniaalves@ uol.com.br

Docente, Universidade Federal de Pernambuco - UFPE - jpj@ formacaohumana.org
} 
confluência da Antropologia Filosófica, da Psicologia e da Educação, objeto este que se revela na possibilidade e necessidade de descortinar seu sentido para a teoria e a prática educacionais, tarefa esta intransferível da Filosofia da Educação.

Além desta justificativa e introdução, este artigo se compõe das seguintes partes: (a) discussão sucinta sobre a ideia de formação humana e suas implicações educacionais; (b) reflexão sobre os aspectos formativos no pensamento de Erikson (c) considerações finais.

Observe, esse modelo já está na formatação. Basta escrever seguindo esse modelo e o seu artigo já estará dentro das normas do evento.

\section{Fundamentação Teórica}

Apesar de sua importância educativa, o tema da formação humana não é dos mais debatidos no campo educacional. No Brasil, podemos citar algumas exceções como Rodrigues (2001), Severino (2006), Röhr (2010), Policarpo Junior e Rodrigues (2010).

Pode-se reconhecer em todos esses autores o entendimento de que a educação não é um processo constituído a esmo ou espontaneamente, mas, ao contrário, provém de uma intenção deliberada de promover, por meio de sua formação, aquilo que no humano pode e deve ser elevado à condição de expressão de sua perfeição ou atualização.

A noção de que a formação humana, naquilo que tange à formação do ente humano como ser pessoal, que se encontra em condições sociais e políticas determinadas, tem como princípio intrínseco uma compreensão normativa que atua como parâmetro de orientação ao processo educativo, de modo próprio e apropriado à natureza do ser humano, como se expressa Galeffi (2003), de modo a conduzi-lo à formação humana de si mesmo, sem violência ao seu ser.

Assim, de acordo com Rodrigues (2001) a Educação é vista como ciência e processo que têm por escopo a formação ética do sujeito; para Röhr (2010, p.13-52) a educação expressa integração do sujeito humano por meio de seu direcionamento espiritual e para Severino(2006) exprime a formação ético-política e cultural do homem, ou, ainda, segundo, Policarpo Júnior e Rodrigues (2010) revela a atualização normativa dos princípios da igualdade, verdade, utilidade, razoabilidade, introspecção, individuação e liberdade pelo ente humano singular.

Apesar da reflexão sobre o sentido e abrangência do ato educativo, segundo o pensamento dos autores mencionados, suas teorizações não entram em consideração quanto ao modo como tais aspectos podem ser apresentados, experimentados e apropriados progressiva e existencialmente pelo ser humano em seu ciclo de vida.

Diante disso, a reflexão empreendida por autores como Erikson, apesar de classificados no cânone científico como psicólogos, revela sua afinidade com a preocupação que direciona o 
pensamento educacional sobre a formação humana, na medida em que o legado intelectual dos primeiros também se estrutura de acordo com princípios formativos que se apresentam aos seres humanos como necessários ao seu próprio desenvolvimento. Revela-se também, nesse autor, a ideia de uma direção normativa do desenvolvimento humano aliada à compreensão de como tal exigência se manifesta ou pode se manifestar ao longo do ciclo de vida humano, de acordo com a educação a que o ser humano tiver acesso e ao modo próprio como responderá pessoal e vivencialmente aos desafios e possibilidades dos estágios definidos em sua trajetória formativa.

Pretende-se, portanto, refletir sobre como os princípios da formação humana se expressam na estrutura do pensamento de Erikson ao longo das etapas do ciclo vital por que passa o ser humano singular.Nesta parte do artigo, o autor deve fazer uma exposição e uma discussão das teorias que foram utilizadas para entender e esclarecer o problema, apresentando-as e relacionando-as com a dúvida investigada. A fundamentação apresentada servirá de base para as análises dos dados, no momento da apresentação e discussão dos resultados.

Os estudos do desenvolvimento realizados por Erikson (1982) estão pautados em teorias psicossociais e reconhecem a necessidade de relações afetivas e comunitárias fortalecidas a partir da infância.

Erikson, em relatos de experiências com histórias de vida e estudos de caso, refere a existência do ser humano a partir da relação entre três níveis de organizações que se interdependem sem, necessariamente, seguir uma ordem rígida: (a) o soma, que representa o corpo, vinculado ao biológico; (b) a psique, que está relacionada aos processos psíquicos das experiências individuais, através do ego, e; (c) o etos, que diz respeito ao que se relaciona à organização cultural. Todos compõem uma abordagem que está vinculada ao humano em sua formação como um todo integrado.

Assim como Freud, Piaget e Sullivan, entre outros escritores, Erikson estudou o desenvolvimento humano a partir de um modelo que apresenta características, segundo Rabello (2001), bem próprias. Vejamos algumas destas características a seguir: o autor em estudo não teorizou a sexualidade como espinha dorsal de suas investigações; os estágios psicossociais vão além da infância e esta, apesar de sua importância, não é determinante no desenvolvimento e, portanto, pode ser transformada ao longo de suas experiências; o ego e o meio social impulsionam para o crescimento em cada estágio, pois as exigências internas e externas se fazem presentes e atuantes nos indivíduos; no Ciclo da vida, o ego experiencia crises que podem se revelar de forma positiva e/ou negativa; em meio ao fluxo dessas experiências, o ego tende a se fortalecer e/ou se fragilizar; a partir de então, a personalidade se reestrutura e se reformula.

Nos estudos psicossociais, as crises vivenciadas pelo ego indicam maturação na relação com o meio social. Essa dinâmica está atrelada aos elementos culturais, às circunstancias e à 
personalidade.

Seguiremos revisitando os estágios que compõem o Ciclo da vida, observando os elementos que se apresentam tensionados entre tendências sintônicas e distônicas. As primeiras, segundo Erikson (1998, p.90), dizem respeito ao crescimento e à expansão do humano e as segundas expressam elementos geradores de conflito ao longo das fases.

Ao refletirmos a respeito do desenvolvimento, em Erikson, percebemos uma relação entre as crises psicossociais e as estruturas que norteiam as metas. Vejamos: na fase que expressa a Confiança básica vs. Desconfiança, a genitora exerce função de provedora, satisfazendo as necessidades vitais do bebê e, nesse percurso, a confiança progressivamente se estrutura de forma positiva e fortalecida, gerando esperança; por outro lado, se essa relação não for integradora, a desconfiança se sobrepõe.

Na Autonomia vs. Vergonha e Dúvida, fase em que a criança explora o mundo em sua volta, há necessidade de apoio do vínculo parental. Este vínculo delimita normas, a fim de que a criança reconheça a relação com o outro e, a partir de então, seja capaz de desenvolver seus potenciais em direção à autonomia. Para tanto, a maturação intelectual e motora necessita de estímulo, visando a potencializar a vontade de descobertas e, ao mesmo tempo, conhecer normatizações não rígidas, pois estas podem produzir uma baixa autoestima em fase posterior. Por outro lado, se a criança não tem uma orientação adequada, provavelmente se sentirá pouco acolhida e, consequentemente, insegura em relação às suas capacidades. O desafio parece ser encontrar a medida das intervenções, quanto ao amparo e à orientação.

$\mathrm{Na}$ etapa da Iniciativa vs. Culpa, há uma influência das fases que desenvolveram positivamente a confiança e a autonomia. A criança faz uso de suas habilidades motoras e intelectuais, através de planos para alcançar objetivos e metas. Nesse momento, amplia o mundo de relações e inicia processos de aprendizagens mais formalizados. Os pais podem facilitar a realização de algumas tarefas ou, na medida do possível, ensejar que outras possam ser realizadas com autonomia, visando ao desenvolvimento de iniciativa e de certa independência para escolhas.

Na etapa Diligência vs. inferioridade, fase que se desenvolve a partir do momento em que a criança experiencia construtivamente as anteriores, no plano da confiança, da autonomia e da iniciativa, a perseverança é um dos indicativos que constitui esse estágio. Muitas vezes, quando há alguma falha nesse caminho, o ego se torna sensível, possibilitando, em alguns casos, o retorno a fases aparentemente superadas. Estimular a criança e facilitar as relações sociais é outro desafio exposto por Erikson.

$\mathrm{Na}$ Identidade vs. confusão de identidade, a adolescência se coloca ativa em seus questionamentos e decisões, se houver um desenvolvimento das fases vividas. É importante 
reconhecer que, na adolescência, as posições ainda são pouco definidas, então é muito comum mudanças. A regressão do ego é, na maioria dos casos, resultado de uma dificuldade de compreensão para o enfrentamento de situações-problema. Quando o adolescente experiencia de forma estruturada esse estágio, ele se revela através de sentimentos que expressam integração consigo e o desenvolvimento de sua identidade tende a ir mais além, na superação positiva da fase.

Intimidade vs. Isolamento, fase que expressa, na sequencia do Ciclo da vida, certa estabilização do ego a partir de experiências positivas. No entanto, no desenvolvimento em que elementos distônicos sobressaem, o ego, possivelmente, se apresentará mais fragilizado para uma abertura à relação com o outro; por exemplo: no vínculo entre pessoas que se amam de modo amadurecido - o amadurecimento aqui implica saber conviver -, se o ente humano, em sua formação, não se apresentar fortalecido, é possível que haja o isolamento, visando à preservação do ego. Essa fragilidade, necessariamente, não implica um dado negativo, desde que seja vivenciado como reelaboração de experiências.

Generatividade vs. Estagnação: nesta etapa, gerar representa a capacidade de produzir, de revelar-se com um olhar de vivências passadas e de crises superadas, acreditando-se que há mais metas a construir e potencializando-se a capacidade de compartilhar com o outro o aprendizado das experiências vividas. Em contrapartida, o indivíduo, quando não se sente acolhido e escutado em suas experiências e, portanto, não encontra espaço para os ensinamentos apreendidos ao longo da vida, sofre um processo de estagnação ou ainda pode usar da autoridade, por ser mais velho, excedendo-se para o autoritarismo, segundo Rabello(2007).

Integridade vs. Desespero: para Erikson, o Ciclo da vida teria alcançado a sua culminância a partir de feedbacks avaliativos, o que representaria reflexão a respeito de uma formação humana integrada e despertaria a necessidade de viver com serenidade. Todavia, a estagnação diante da ausência de um propósito elevado de vida pode criar um caminho no qual o indivíduo se desespere diante da morte. Tais circunstâncias podem representar uma teia de produções nostálgicas, em razão da percepção negativa da velhice, ao invés de considerar a sabedoria revelada pelos anos. No entanto, segundo Rabello (2007), algumas expressões negativas dessa fase também se apresentam ao longo da experiência de vida e da idade, quando afirmadas com o objetivo de sobrepor a "sabedoria" do mais velho aos mais novos, com o propósito de conduzir decisões.

O nono estágio, que envolve o ser ancião a partir dos oitenta anos, elege como desafio, segundo Erikson (1998, p.vii), a "sabedoria" e a "integridade" como as forças finais que amadureceriam plenamente na velhice. $\mathrm{O}$ sentido desse desafio perpassa pelo acesso à realidade que nos constitui singular e coletivamente. Nesse contexto, (idem, p.xi/xii)... "Florescem o amor, a devoção e a amizade, a tristeza é terna e enriquecedora; a beleza dos relacionamentos é 
profundamente prazerosa. Olhar para trás é atraentemente memorável; o presente é natural e cheio de pequenos prazeres, imensas alegrias e muito riso."

A clareza dos desafios propostos, tendo em vista a sabedoria e a integridade, reafirma a adequação de viver a consciência das limitações provenientes da idade. A existência requer reflexões que expressam presente, passado e futuro vivos em um corpo, que simboliza parte da condição humana de ser além do self.

É possível que o enfrentamento do desespero com humildade e aceitação apropriadas seja a forma mais adequada de expressão da sabedoria. A partir desse princípio, a nona etapa do Ciclo será revivida em um esforço contínuo de controle, mesmo que parcial, sobre o corpo e as habilidades psíquicas. Joan Erikson percebeu a importância e a força dos elementos distônicos sobre os sintônicos, diferentemente dos estágios anteriores, porém ratifica que, independente da etapa, o conflito e a tensão podem se tornar para o ser pessoal fontes de crescimento, força e compromisso humano.

A Desconfiança básica se intensifica, sobrepondo-se, quase sempre, à Confiança. A instabilidade corpórea e temporal abre espaço para a desesperança. As dificuldades e os conflitos se apresentam crescentes frente a atividades simples do cotidiano. A Autonomia se encontra, nesse estágio, mais fragilizada, pois as habilidades vitais e sociais já não respondem como antes, o que gera dependência. Nesse contexto, a Vergonha pela perda do autocontrole e a dúvida em relação às potencias vitais do corpo e da mente põem à prova a autonomia.

A Iniciativa se torna parte da memória e é amortecida pelo ritmo lento da idade. A culpa surge quando o ancião se envolve em projetos aparentemente satisfatórios, mas, apenas, do ponto de vista individual. A Diligência vs. Inferioridade referencia a competência, na realização das capacidades. Exige-se, com rigor, adequação pela imposição da idade. Isso pode gerar um sentimento de inferioridade, pois as habilidades estão comprometidas e nem sempre dão conta das necessidades próprias de determinadas competências, o que pode vir a provocar um sentimento de depreciação.

A Identidade vs. Confusão de identidade: fidelidade. Nesse momento, questiona-se a própria existência no mundo. A confusão se dá quando não há a consciência genuína do status e do papel a desempenhar. A fidelidade aos propósitos anteriores se torna imprecisa. Intimidade vs. Isolamento: amor. Há, nessa etapa, para alguns, dificuldade de estabelecer vínculo com o outro, se não existirem motivação e estímulos à convivência. $\mathrm{O}$ isolamento se dá quando não há uma história de relações significativas, seja no campo do amor ou da arte.

Generatividade vs. Estagnação: cuidado. As capacidades são diminuídas, abre-se espaço para um sentimento de inutilidade. Se os desafios, para alguns, se tornarem escassos ou não 
existirem, há representação de descanso e, para outros, uma perda, pois pode implicar a negação do exercício da criatividade, responsabilidade etc.

Integridade vs. Desespero e Desgosto: sabedoria. Nessa fase, ainda, quando os elementos distônicos e sintônicos alcançam um equilíbrio, há possibilidade de valores materiais e racionais se transformarem, imprimindo, nesse percurso, uma forma mais espiritualizada de ser no mundo. E, com isso, há reelaboração do tempo, do espaço e da própria vida. Libertar-se das tensões pode ser uma maneira de encontrar a paz e aceitar as transformações inerentes à identidade temporal. $\mathrm{O}$ cotidiano é um desafio, a morte está muito próxima, mas, se a confiança básica estiver bem estruturada, a capacidade de superação dos desafios estará presente e redesenhando um modus vivendi, mesmo em meio a uma sociedade que, nessa etapa, quase sempre, não integra o velho às comunidades.

Ao longo desse percurso, é possível perceber que a formação humana se exerce como integrada à educação, concebida em sentido amplo, e se manifesta por meio da autopercepção e cuidado de si. Tal compreensão se associa ao exercício filosófico de que o homem seja capaz de articular de modo unificado suas dimensões (físicas, sensoriais, emocionais, mentais, espirituais) em si mesmo, como afirma Röhr (2010), o que pressupõe a capacidade de o homem refletir sobre a sua atuação no mundo e sobre ele mesmo. Este diálogo entre o Eu e o meio embasa a intencionalidade de formar o conceito apropriado de educação para a formação humana a partir da concepção de que se deve atingir uma determinada condição que ainda não se encontra desenvolvida, atualizada ou presente, como nos dizem Policarpo Júnior e Rodrigues (2010).

Dando continuidade à argumentação, a Educação, em seu sentido estrito, não pode se exercer sem que promova o desenvolvimento psicossocial e moral do ser humano. Porém, para que isso ocorra, é necessário que haja acesso e compreensão aos parâmetros éticos que embasam a prática de uma convivência harmônica entre pares. Nesse sentido, o ato educativo não se restringe apenas à socialização e à formação da identidade, mas se transpõe ao nível mais elevado de compreensão e comprometimento com os valores normativos da educação voltada à formação humana.

\section{Conclusões}

Os legados de Erikson quanto ao desenvolvimento em seu ciclo vital expressam, que: (a) há um sentido desejável e evolutivo em tal processo; (b) tal desenvolvimento acontece na interação entre o ser singular e a comunidade/sociedade humana, havendo aspectos que se originam do próprio ego em formação e outros que emergem do contexto social em que este se encontra; (c) o ciclo vital do ente singular pode vir a ser bem sucedido ou fracassar ou, em outras palavras, 
promover a integração do ente particular e, portanto, sua formação humana, ou deixar-se estagnar, regredir, e, consequentemente, mergulhar na negatividade ou destrutividade; (d) a formação humana - expressa no alcance bem sucedido dos estágios superiores de desenvolvimento - realiza-se mediante o enfrentamento e superação de forças que representam aquilo que há de negativo, regressivo ou primitivo no próprio ser humano e também no ambiente em que vive.

Além desses aspectos, a compreensão evolutiva dos estágios do desenvolvimento humano pelos autores mencionados aponta igualmente para o fato de que apenas aqueles que alcançam os estágios mais elevados se encontram na condição própria de contribuir para o aperfeiçoamento social, quer por meio da capacidade de se comprometer incondicionalmente com os ideais de justiça, compaixão e bondade, quer pela capacidade de gerar atitudes favoráveis e necessárias ao bem comum, como o cuidado e a caridade com aquilo que precisa de proteção e direcionamento para germinar, crescer e dar frutos positivos no espaço social, segundo Erikson, único modo de alcançar a sabedoria e superar o desespero de uma vida sem sentido.

Embora os estágios descritos pelo autor em pauta guardem relativa correspondência com o desenvolvimento etário, ele mesmo afirma não haver rigidez em tal ordenamento, de forma que qualidades não alcançadas em seu estágio esperado podem vir a ser desenvolvidas posteriormente, a despeito da maior dificuldade para tais realizações serem então atingidas. De todo modo, realizações superiores não poderiam ser alcançadas sem outras que lhes deveriam anteceder, como, por exemplo, a atitude positiva de cuidar e gerar vida não pode se exercer sem que o sujeito humano seja capaz de amar e de estabelecer vínculos profundos com outros entes, segundo Erikson, assim como a atitude pessoal de comprometer-se com os princípios de justiça e compaixão não pode atualizar-se sem que o sujeito particular tenha alcançado o respeito pelas normas que regem o contrato social entre humanos (KOHLBERG, 2002)

Finalizando, a elucidação sobre os fins formativos da educação pode ser ricamente ampliada quando ficam esclarecidas etapas processuais importantes e necessárias à afirmação da formação humana dos sujeitos singulares, compreendendo-as como superações e inclusões sucessivas das crises e tendências diversas que jazem no interior do homem e que são atualizadas e reapresentadas pelo contexto social ao longo do ciclo vital dos entes humanos. A apreensão de tais sentidos e a compreensão daquilo que cada um precisa vir a enfrentar em prol de sua maior individuação ou integração fortalecem o sentido do educar, ao mesmo tempo em que põem em relevo a magnitude e desafio de sua realização. 


\section{Referências}

BIAGGIO, Angel amaria Brasil. Lawrence Kohlberg - Ética e educação moral. São Paulo: Moderna, 2002.

ERIKSON, Erik. O ciclo de vida completo.(trad.) Maria Adriana Veríssimo Veronese. Porto Alegre: artes Médicas, 1998.

GALEFFI, Dante Augusto. Filosofar \& Educar - inquietações pensantes. Salvador: Quarteto, 2003.

GALEFFI, Dante Augusto. O Rigor nas pesquisas qualitativas: uma abordagem fenomenológica em chave transdisciplinar. In.: MACEDO, Roberto Sidnei (org.). Um Rigor Outro sobre a questão da qualidade na pesquisa qualitativa. Salvador: EDUFBA, 2009. pp.13-73.

POLICARPO JUNIOR, José; RODRIGUES, Maria Lucicleide Falcão de Melo. Princípios orientadores da formação humana: dimensão normativa da educação. Paidéia (Ribeirão Preto), Ribeirão Preto, v. 20, n.45, Apr. 2010.

RABELLO, Elaine. Personalidade: estrutura, dinâmica e formação - um recorte eriksoniano. Escola Politécnica de Saúde Joaquim Venâncio, Fundação Oswaldo Cruz, Rio de Janeiro, 2001. (monografia).

RABELLO, Elaine; PASSOS, José Silveira. Erikson e a teoria psicossocial do desenvolvimento. Disponível em< http://www.josesilveira.com/artigos/erikson.pdf $>$ Acesso em 20 de mai. 2011.

RODRIGUES, Neidson. Educação: da formação humana à construção do sujeito ético. Educ. Soc., Campinas, v. 22, n. 76, Oct.2001.

RÖHR, Ferdinand (org.). Diálogos em Educação e Espiritualidade. Recife: Ed. Universitária da UFPE, 2010.

SEVERINO, Antônio Joaquim. A busca do sentido da formação humana: tarefa da Filosofia da Educação. Educ. Pesqui., São Paulo, v. 32, n. 3,Dec. 2006. 